\title{
Risk indicators for aggressive periodontitis in an untreated isolated young population from Brazil
}

Priscila Corraini(a)

Cláudio Mendes Pannuti ${ }^{(b)}$

Alessandro Nautili Pustiglioni(a)

Giuseppe Alexandre Romito(b)

Francisco Emílio Pustiglioni ${ }^{(b)}$

(a) $\mathrm{MSc}_{\text {; }}{ }^{\text {(b) }} \mathrm{PhD}$ - Division of Periodontics, School of Dentistry, University of São Paulo, SP, Brazil.

\section{Corresponding author:}

Priscila Corraini

Disciplina de Periodontia, Departamento de Estomatologia, Faculdade de Odontologia da Universidade de São Paulo

Av. Professor Lineu Prestes, 2227, Cidade

Universitária

São Paulo - SP - Brazil

CEP: 05508-900

E-mail: priscilacorraini@gmail.com or pcorraini@usp.br

\begin{abstract}
This study aimed to assess the prevalence of aggressive periodontitis (AgP), and to investigate the association between demographic, socioeconomic and behavioral risk indicators with $\mathrm{AgP}$ in an untreated and isolated young population in Southeastern Brazil. For this cross-sectional survey, 134 subjects aged 12-29 years were selected by a census. Of those eligible, 101 subjects received a full-mouth clinical examination, and were interviewed using a structured written questionnaire. Cases were defined as individuals with 4 or more teeth with attachment loss $\geq 4 \mathrm{~mm}$ or $\geq 5 \mathrm{~mm}$ in the age groups $12-19$ and 20-29, respectively. Overall, $9.9 \%$ of the subjects presented $\mathrm{AgP}(10.3 \%$ of the $12-19$-yearolds and $9.7 \%$ of the $20-29$-year-olds). The only risk indicator significantly associated with $\mathrm{AgP}$ in this isolated population was a high proportion of sites $(>30 \%)$ presenting supragingival calculus [OR $=23.2]$. Having experienced an urgency dental treatment was a protective factor for AgP [OR = 0.1]. The authors concluded that this isolated and untreated population from Brazil presented a high prevalence of AgP. Local plaque-retaining factors played a major role in the prevalence of $\mathrm{AgP}$ in this isolated population, and should be included in further studies evaluating this destructive periodontal disease form.
\end{abstract}

Descriptors: Periodontitis / epidemiology; Risk factors. 


\section{Introduction}

Aggressive periodontitis $(\mathrm{AgP})$ is a periodontal disease characterized by a rapid progression rate, leading to pronounced tooth loss. ${ }^{1}$ AgP prevalence varies greatly among different populations worldwide. In a general perspective of all epidemiological studies including young subjects, lower prevalence estimates $(<1 \%)$ have been found among Caucasian subjects living in developed countries in comparison to subjects living in developing countries ( 0.5$5 \%) .{ }^{2}$ However, an aspect that hinders the interpretation of epidemiologic data concerning $\mathrm{AgP}$ is that the parameters used for assessing identification of cases vary greatly among surveys. ${ }^{3,4}$

Data regarding the determinants of $\mathrm{AgP}$ are few and still inconclusive, pointing out for the presence of multiple factors. Genetic predisposition ${ }^{3,5}$ and specific microbiota ${ }^{6-8}$ have been shown to increase the risk of disease occurrence. Age, ${ }^{9}$ certain ethnic groups, ${ }^{10}$ low socioeconomic status, ${ }^{3,11}$ poor oral hygiene, ${ }^{12}$ local plaque-retaining factors ${ }^{11}$ and smoking $^{11,13}$ have also been associated with destructive periodontal disease in young subjects.

Data from isolated populations are important for the assessment of risk factors because a considerable control of confounding factors is obtained, to a certain extent, by the natural restriction in terms of influences from the effects of dental treatment, use of antibiotics, and oral hygiene procedures. ${ }^{14}$ Therefore, the aim of the present study was to estimate the prevalence of $\mathrm{AgP}$ and to investigate the associations between demographic, socioeconomic and behavioral risk indicators and $\mathrm{AgP}$ in an untreated and isolated young population in Brazil.

\section{Material and Methods Study population}

A cross-sectional study was conducted, targeting a population who lives at the micro-area Cajaíba, which belongs to the city of Paraty, state of Rio de Janeiro, located in the southeastern area of Brazil. This particular population was selected for their isolation and for not having received regular dental care nor been the target of preventive programs. Dental care in that community has generally been restricted to the relief of pain.
Since no relevant updated information of the target population was available at the beginning of the study, it was decided that a census should be performed. ${ }^{15}$ This census revealed that the actual population of Cajaíba comprised 358 inhabitants in 2006 (205 males and 153 females). It was decided that the study population should be comprised of individuals aged 12 years onward, because that is the age in which, in most cases, all the permanent teeth are completely erupted. Thus, the target population for this particular study was drawn from subjects within the 12-29 years age bracket, comprising 134 inhabitants.

\section{Ethical considerations}

Permission to carry out this study was obtained from each one of the beach community leaders of Cajaíba, as well as from the mayor of Paraty. The study protocol and the informed consent form were approved by the Ethics Committee of the University of São Paulo. Owing to a high frequency of illiteracy, the informed consent form was read to all eligible individuals. All subjects who agreed to participate or, in the case of children, an adult guardian - were asked to sign the informed consent form to attest to their understanding of its contents and acceptance to participate in the study. As a large need for dental treatment was expected, a partnership was established with the NGO "Sorriso Marinho". Whenever needed, pain-relief treatment was administered by a dentist from this NGO. Subjects detected with diseases or conditions of non-dental origin were referred to the nearest health center located in Paraty.

\section{Interviews and clinical examinations}

All eligible and consenting subjects were visited at home and invited to participate in an interview performed by a trained dental assistant based on a structured written questionnaire. The following information was collected through the interview: age (years), gender, occupation, household size, presence of cash-income (yes/no) and, if applicable, its approximate monthly amount in Brazilian currency ("reais"), illiteracy (yes/no), years of education, and if they had ever received urgency treatment (yes/no). The frequency of tooth cleaning and smoking habits 
were also investigated. The participants were identified by questions as either current smokers (had smoked $\geq 100$ cigarettes in their lifetime and currently smoked), former smokers (had smoked $\geq 100$ cigarettes in their lifetime, but were not currently smoking) or never smokers (had not smoked $\geq 100$ cigarettes in their lifetime). ${ }^{16}$ Other questions pertaining to smoking habits included the duration of current and former smoking (years); time since cessation for former smokers (years), type of tobaccocontaining items used, as well as the number of items smoked on a daily basis.

The clinical examinations were carried out by a single periodontal specialist (PC) assisted by a scribe. All clinical examinations were performed under field conditions in the households of the consenting participants using natural daylight and a headlamp (Dark, Azteq, São Paulo, SP, Brazil) as source of illumination.

Probing depth (PD), measured as the distance $(\mathrm{mm})$ from the free gingival margin (FGM) to the bottom of the pocket; and gingival recession (GR), measured as the distance from the cementum-enamel junction (CEJ) to the FGM, were determined at 6 sites per tooth (mesiobuccal, midbuccal, distobuccal, distolingual, midlingual, and mesiolingual sites) in all permanent teeth present, excluding third molars, using a mouth mirror (Mirror $n^{\circ} \# 5$, Hu Friedy, Chicago, IL, USA) and a manual periodontal probe (PCPUNC-15, Hu Friedy, Chicago, IL, USA). The measurements were rounded to the lowest whole $\mathrm{mm}$. When the CEJ was located coronally to the FGM, it was given a negative sign. Clinical attachment level (CAL) was calculated as the sum of the PD and GR values for each site. Two sites per tooth (midbuccal and midlingual) were assessed for the presence of visible plaque (yes/no) and supragingival calculus (yes/no). Supragingival calculus was defined as calcified deposits located on exposed crowns and root surfaces extending up to $1 \mathrm{~mm}$ below the FGM. Excessive amounts of supragingival calculus compromising assessment of the periodontal conditions were removed by periodontal curettes (Gracey $\mathrm{Cu}$ rettes, Hu Friedy, Chicago, IL, USA) before probing.

Diabetes was assessed by measurements of the casual plasma glucose concentrations (PGC) in mg/
dL using a device (Accu-Chek Active, Roche, São Paulo, SP, Brazil). The diagnostic criteria employed was a casual PGC $\geq 200 \mathrm{mg} / \mathrm{dL}$, confirmed on the following day by fasting. ${ }^{17}$

\section{Measurement reproducibility}

The clinical examiner was trained and calibrated for the clinical examinations 15 days before and 4 months after the start of the study. Intra-examiner reproducibility assessments were carried out under the same field conditions used in all clinical examinations, and was assessed by double recordings in 13 subjects (545 sites) ( $6 \%$ of the study population). The repeat recordings were made 7 days after the first clinical examination. The intra-class correlation coefficient at the site level ranged between 0.93 and 0.95; at the subject level for mean CAL, it ranged between 0.98 and 0.99 .

\section{Data analysis}

In this study, the following case definitions of AgP were employed:11 (1) Age group 12-19 years: subjects with $\mathrm{CAL} \geq 4 \mathrm{~mm}$ in $\geq 4$ teeth; (2) Age group 20-29 years: subjects with $\mathrm{CAL} \geq 5 \mathrm{~mm}$ in $\geq 4$ teeth. Midbuccal and midlingual surfaces were not excluded from the analysis, since the tradition of oral hygiene habits was extremely limited in this population. Moreover, the data were also presented as prevalence and extent of CAL and $\mathrm{PD} \geq 4 \mathrm{~mm}, \geq 5 \mathrm{~mm}$, and $\geq 6 \mathrm{~mm}$. Extent was defined as the percentage of sites affected per person.

The candidate predictor variables considered for inclusion in a logistic regression analysis included age (12-19/20-29); gender; cash-income (yes/no); education years ( $\leq 4$ years/ $>4$ years), illiteracy (yes/ no); presence of pain-relief treatment (yes/no); \% of sites with visible plaque $(\leq 70 \% />70 \%)$; $\%$ of sites with supragingival calculus $(\leq 30 \% />30 \%)$; diabetes (yes/no); as well as smoking status (non-smoker/ smoker). Exposure to smoking was accounted for by current and former smokers combined. The tobacco containing items used in the study population included commercial cigarettes or hand-rolled cigarettes, and in a few cases Cannabis or pipes.

To explore and quantify the association between the candidate predictor variables and the periodon- 
tal outcome variable (AgP presence), a multivariable logistic regression analysis was performed using the "logit" procedure in the STATA program (Stata 9.2 for Windows, Stata Corporation, College Station, TX, USA). All candidate predictor variables associated with the outcome at $p<0.25$, as evidenced in a univariable logistic regression analysis, were included in the full model. Predictor variables were removed from the model one at a time, until the loglikelihood ratio test ${ }^{18}$ indicated that no more variables could be removed. A variable was considered a confounder if its removal from the model resulted in changes in the $\beta$ estimates by more than $15 \%$. Model fit was evaluated using the Hosmer \& Lemeshow Goodness-of-fit-test ${ }^{18}$ and by calculation of the area under the ROC curve, which describes the ability of the logistic model to correctly predict outcome variable status.

\section{Results}

A total of 134 subjects were eligible for examination in this survey. Of these, $101(76 \%)$ were clinically examined and participated in the interview (Table 1). Nine subjects were interviewed but refused to be clinically examined, 3 refused both in- terview and clinical examination and 21 were not at home. The non-respondents were mostly males aged 20-29 years, and the probable reason for not responding was their constant absence because they were out fishing. There were no complete edentulous subjects. The mean number of teeth present was 25.2 [24.6;25.8], which tended to decrease with increasing age.

The overall prevalence of $\mathrm{AgP}$ was $9.9 \%, 10.3 \%$ in the $12-19$-year-olds, and $9.7 \%$ in the $20-29$ year-olds (Table 1). It was not followed by an age gradient, with the prevalence decreasing in the 20 29-year-old females and increasing in the 20-29year-old males. When the disease pattern was expressed by prevalence of CAL and PD and extent as mean \% of sites with CAL (Table 2 and Graph 1), the frequency distribution followed a clear gradient towards an increased prevalence and \% of sites affected with increasing age for all thresholds of CAL and PD.

Graph 2 shows that both visible plaque and supragingival calculus were highly prevalent and extensive in all age groups. For both plaque and supragingival calculus deposits a clear age-related gradient towards an increased proportion of sites

Table 1 - Study population distribution, edentulism frequency, mean number of teeth present and $\mathrm{AgP}$ prevalence according to age and gender.

\begin{tabular}{|c|c|c|c|c|c|c|c|c|}
\hline \multirow{2}{*}{$\begin{array}{l}\text { Age } \\
\text { (years) }\end{array}$} & \multirow{2}{*}{ Gender } & \multirow{2}{*}{$\mathrm{N}$} & \multirow{2}{*}{$\%$} & \multirow{2}{*}{$\begin{array}{c}\% \\
\text { target } \\
\text { population }\end{array}$} & \multirow{2}{*}{$\begin{array}{c}\% \\
\text { edentulism }\end{array}$} & \multirow{2}{*}{$\begin{array}{c}\text { mean number of } \\
\text { teeth present } \\
{[95 \% \mathrm{Cl}]}\end{array}$} & \multicolumn{2}{|c|}{$\mathrm{AgP}$ Prevalence } \\
\hline & & & & & & & $\%$ & $\mathrm{~N}$ \\
\hline \multirow{2}{*}{$12-19$} & Male & 21 & 53.8 & \multirow{2}{*}{78} & 0 & $25.7[24.4 ; 27.0]$ & 9.5 & 2 \\
\hline & Female & 18 & 46.2 & & 0 & $26.3[25.5 ; 27.2]$ & 11.1 & 2 \\
\hline \multirow{2}{*}{$20-29$} & Male & 31 & 50 & \multirow{2}{*}{74} & 0 & $24.6[23.8 ; 25.5]$ & 12.9 & 4 \\
\hline & Female & 31 & 50 & & 0 & $24.8[23.4 ; 26.2]$ & 6.5 & 2 \\
\hline \multicolumn{2}{|l|}{ Total } & 101 & 100 & 76 & 0 & $25.2[24.6 ; 25.8]$ & 9.9 & 10 \\
\hline
\end{tabular}

Table 2 - Prevalence (\%) and extent of periodontal attachment loss and probing depth $\geq 4 \mathrm{~mm}, \geq 5 \mathrm{~mm}$, and $\geq 6 \mathrm{~mm}$, according to age and gender. Extent, here, was expressed as the mean proportion of sites affected.

\begin{tabular}{|c|c|c|c|c|c|c|c|c|c|c|}
\hline \multirow{2}{*}{$\begin{array}{l}\text { Age } \\
\text { (years) }\end{array}$} & \multirow{2}{*}{$\mathrm{N}$} & \multicolumn{3}{|c|}{$\mathrm{CAL} \geq 4 \mathrm{~mm}$} & \multicolumn{3}{|c|}{$\mathrm{CAL} \geq 5 \mathrm{~mm}$} & \multicolumn{3}{|c|}{$\mathrm{CAL} \geq 6 \mathrm{~mm}$} \\
\hline & & $\%$ & Extent & $95 \% \mathrm{Cl}$ & $\%$ & Extent & $95 \% \mathrm{Cl}$ & $\%$ & Extent & $95 \% \mathrm{Cl}$ \\
\hline $12-19$ & 39 & 33.3 & 0.8 & {$[0.3 ; 1.3]$} & 7.7 & 0.1 & {$[0.0 ; 0.2]$} & 5.1 & 0.1 & {$[0.0 ; 0.1]$} \\
\hline $20-29$ & 62 & 62.9 & 4.7 & {$[1.9 ; 7.5]$} & 37.1 & 2.0 & {$[0.0 ; 3.9]$} & 21.0 & 0.9 & {$[-0.3 ; 2.0]$} \\
\hline \multirow{2}{*}{$\begin{array}{c}\text { Age } \\
\text { (years) }\end{array}$} & \multirow{2}{*}{$\mathrm{N}$} & \multicolumn{3}{|c|}{$\mathrm{PD} \geq 4 \mathrm{~mm}$} & \multicolumn{3}{|c|}{$P D \geq 5 \mathrm{~mm}$} & \multicolumn{3}{|c|}{$\mathrm{PD} \geq 6 \mathrm{~mm}$} \\
\hline & & $\%$ & Extent & $95 \% \mathrm{Cl}$ & $\%$ & Extent & $95 \% \mathrm{Cl}$ & $\%$ & Extent & $95 \% \mathrm{Cl}$ \\
\hline $12-19$ & 39 & 53.9 & 1.4 & {$[0.5 ; 2.3]$} & 5.1 & 0.1 & {$[0.0 ; 0.1]$} & 5.1 & 0.0 & {$[0.0 ; 0.1]$} \\
\hline $20-29$ & 62 & 59.7 & 3.1 & {$[1.5 ; 4.7]$} & 30.7 & 0.8 & {$[0.2 ; 1.3]$} & 14.5 & 0.2 & {$[0.0 ; 0.5]$} \\
\hline
\end{tabular}


affected was observed with increased age. AgP subjects presented a higher proportion of sites with plaque and calculus in comparison to non-AgP subjects in all age groups.

The final multivariable logistic regression model is shown in Table 3. The analysis suggested a significant association between presence of urgency treatment $(\mathrm{OR}=0.1$ [0.0-0.7]) and a high proportion of sites with supragingival calculus $(\mathrm{OR}=23.2$ [2.4225.5]) and AgP.

\section{Discussion}

The results of the present study demonstrate that AgP was highly prevalent among young individuals of an isolated and untreated Brazilian population. In

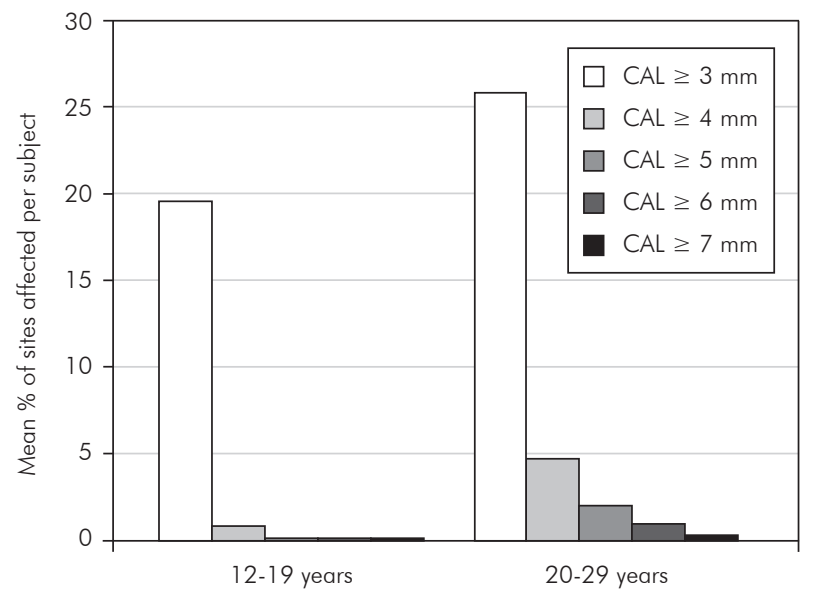

Graph 1 - Mean \% of sites with CAL according to age.

A

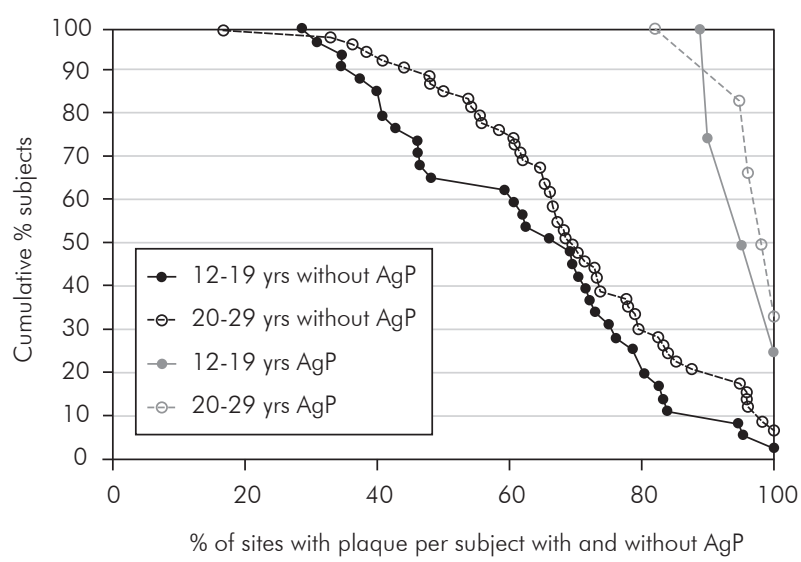

this study, the overall prevalence of $\mathrm{AgP}$ was $9.9 \%$, $10.3 \%$ in the $12-19$-year-olds group, and $9.7 \%$ in the 20-29-year-olds group.

In Latin America, López et al. ${ }^{12}$ (2001) found prevalence estimates of 4.5 and $3.7 \%$ of CAL $\geq 3 \mathrm{~mm}$ in all sites and only interproximal sites, respectively, in a representative sample of high school students from Chile, in contrast to the $100 \%$ estimate found in this study. In Brazil, AgP prevalence has been observed in the age group of 12-19 years ranging from $0.3 \%^{8}$ to $2.5 \% .{ }^{19}$ However, these studies employed different clinical examination approaches and inconsistent definition criteria for AgP. ${ }^{2}$ More recently, Susin, Albandar ${ }^{11}$ (2005), employing a full-mouth clinical examination of 6 sites excluding midbuccal sites, observed an $\mathrm{AgP}$ prevalence of $5.5 \%$ in 14 to 29 years-old city dwellers from Southern Brazil, the highest rate found for a Brazilian population, but still slightly lower than the estimate found in the present study.

In other isolated and untreated populations, prevalence estimates of $16.3 \%$ for $\mathrm{CAL} \geq 4 \mathrm{~mm}$ were found in a group of 14-19-year-old Navajo Indians from New Mexico, ${ }^{20}$ contrasting with the prevalence of $40 \%$ found in the present study, and Timmerman et al. ${ }^{7}$ (2000) observed CAL $\geq 5 \mathrm{~mm}$ in $8 \%$ of $15-25$ year-old Indonesia tea-workers, contrasting with our finding of $19 \%$ for the same age grouping and CAL thresholds.

It should be noted that classification criteria have

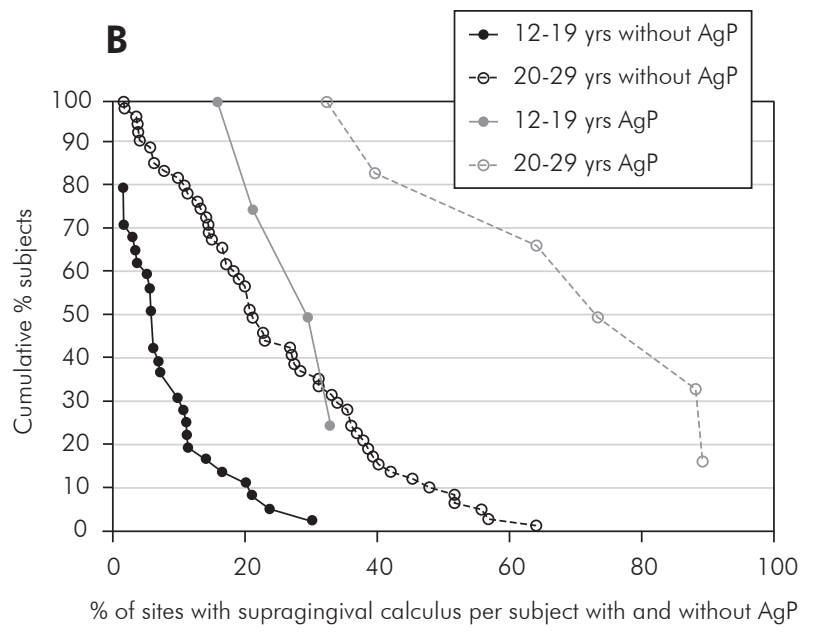

Graph 2 - Percentage of sites with plaque (A) and calculus (B) per subject. 
Table 3 - Final multivariable logistic regression model for AgP.

\begin{tabular}{|c|c|c|c|}
\hline \multirow{2}{*}{ Predictor } & \multirow{2}{*}{ Levels } & \multicolumn{2}{|c|}{$\mathrm{AgP}$} \\
\hline & & OR & $95 \% \mathrm{Cl}$ \\
\hline \multirow{2}{*}{ Age (years) } & $12-19$ & ref & - \\
\hline & $20-29$ & 0.3 & {$[0.1 ; 3.2]$} \\
\hline \multirow{2}{*}{ Ever treated by a dentist? } & No & ref & - \\
\hline & Yes & 0.1 & {$[0.0 ; 0.7]$} \\
\hline \multirow{2}{*}{ Supragingival Calculus \% } & $\leq 30 \%$ & ref & - \\
\hline & $>30 \%$ & 23.2 & {$[2.4 ; 225.5]$} \\
\hline \multicolumn{2}{|l|}{$\begin{array}{l}\text { Hosmer-Lemeshow } \\
\text { Goodness-of-fit test } \\
\text { Statistics }\end{array}$} & \multicolumn{2}{|c|}{$\begin{aligned} \mathrm{Chi}^{2} & =3.55 \\
\mathrm{df} & =4 \\
p & =0.47\end{aligned}$} \\
\hline ROC - Area Under Curve & & \multicolumn{2}{|c|}{0.86} \\
\hline
\end{tabular}

a significant impact on the reported prevalence of disease, and this is particularly true for $\mathrm{AgP} .{ }^{12}$ In addition, the use of partial recording protocols in some studies may underestimate the true prevalence of AgP, particularly in populations with low occurrence of the disease. ${ }^{21} \mathrm{We}$, therefore, used a more strict attachment loss threshold aiming to increase the specificity of the diagnostic criteria of $\mathrm{AgP}$ and to compare with other Brazilian studies available. ${ }^{11}$

The underlying cause of an increased susceptibility for early onset forms of destructive periodontal diseases is still unknown. Many reports suggest that $\mathrm{AgP}$ subjects generally form very little supragingival dental plaque or calculus. ${ }^{22}$ However, few studies have assessed the effect of local plaque-retaining factors in the occurrence of periodontal attachment loss in young age cohorts. In this particular study, confirming other results, ${ }^{10,11}$ a high proportion of sites presenting supragingival calculus was significantly associated with $\mathrm{AgP}$ in the final multivariable regression model. On the other hand, traditional risk factors for periodontal disease, such as smoking, were not associated with $\mathrm{AgP}$ in the present study. The few subjects living in this isolated popu-

\section{References}

1. Brown LJ, Albandar JM, Brunelle JA, Löe H. Early-onset periodontitis: Progression of attachment loss during 6 years. J Periodontol. 1996 Oct;67(10):968-75. lation (358 subjects), leading to a few subjects with the outcome included in a multivariable logistic regression model may have not allowed the identification of other risk indicators for AgP in this study.

Nevertheless, other important risk indicators for AgP such as specific microbiota and genetic predisposition to the effect of the behavioral exposures were not evaluated in this study, factors that could also explain the high occurrence of $\mathrm{AgP}$ found in these young subjects. However, additional studies are required to confirm or refute this interpretation.

\section{Conclusion}

The authors concluded that local plaque-retaining factors can play an important role in the occurrence of $\mathrm{AgP}$, and should be included in further studies evaluating this destructive periodontal disease form.

\section{Acknowledgements}

The study was partly funded by FAPESP (State of São Paulo Research Foundation), grant number 04/15287-4, and by CAPES (Coordination for the Development of Higher Education Personnel).
2. Albandar JM, Tinoco EM. Global epidemiology of periodontal diseases in children and young persons. Periodontol 2000. 2002;29:153-76.

3. Albandar JM, Rams TE. Risk factors for periodontitis in children and young persons. Periodontol 2000. 2002;29:207-22. 
4. Lopez R, Baelum V. Classifying periodontitis among adolescents: implications for epidemiological research. Community Dent Oral Epidemiol. 2003 Apr;31(2):136-43.

5. Kinane DF, Hart TC. Genes and gene polymorphisms associated with periodontal disease. Crit Rev Oral Biol Med. 2003;14(6):430-49.

6. Haubek D, Ennibi OK, Abdellaoui L, Benzarti N, Poulsen S. Attachment loss in Moroccan early onset periodontitis patients and infection with the JP2-type of A. actinomycetemcomitans. J Clin Periodontol. 2002 Jul;29(7):657-60.

7. Timmerman MF, Van der Weijden GA, Abbas F, Arief EM, Armand S, Winkel EG et al. Untreated periodontal disease in Indonesian adolescents. Longitudinal clinical data and prospective clinical and microbiological risk assessment. J Clin Periodontol. 2000 Dec;27(12):932-42.

8. Tinoco EM, Beldi MI, Loureiro CA, Lana M, Campedelli F, Tinoco NM et al. Localized juvenile periodontitis and Actinobacillus actinomycetemcomitans in a Brazilian population. Eur J Oral Sci. 1997 Fev;105(1):9-14.

9. Albandar JM, Muranga MB, Rams TE. Prevalence of aggressive periodontitis in school attendees in Uganda. J Clin Periodontol. 2002 Sep;29(9):823-31.

10. Albandar JM, Brown LJ, Löe H. Clinical features of early-onset periodontitis. J Am Dent Assoc. 1997 Oct;128(10):1393-9.

11. Susin C, Albandar JM. Aggressive Periodontitis in an Urban Population in Southern Brazil. J Periodontol. 2005 Mar;76(3):468-75.

12. López R, Fernández O, Jara G, Baelum V. Epidemiology of clinical attachment loss in adolescents. J Clin Periodontol. 2001 Dec;72(12):1666-74.

13. Hashim R, Thomson WM, Pack ARC. Smoking in adolescence as a predictor of early loss of periodontal attachment. Community Dent Oral Epidemiol. 2001 Apr;29:130-5.
14. Van Der Velden U, Abbas F, Armand S, Loos BG, Timmerman MF, Van der Weijden GA et al. Java project on periodontal diseases. The natural development of periodontitis: risk factors, risk predictors and risk determinants. J Clin Periodontol. 2006 Aug;33(8):540-8.

15. Levy PS, Lemeshow S. Sampling of populations. Methods and applications. $3^{\text {rd }}$ ed. New York: John Wiley \& Sons, Inc; 1999.

16. Centers for Disease Control and Prevention. Cigarette smoking among adults - United States, 1992, and changes in the definition of current cigarette smoking [published erratum appears in MMWR Morb Mortal Wkly Rep. 1994;43:801-3]. MMWR Morb Mortal Wkly Rep. 1994 May;43:342-6.

17. Expert Committee on the Diagnosis and Classification of Diabetes Mellitus. Report of the Expert Committee on the Diagnosis and Classification of Diabetes Mellitus. Diabetes Care. 2003 Jan;26(Suppl 1):S5-20.

18. Hosmer D, Lemeshow S. Applied Logistic Regression. $2^{\text {nd }}$ ed. New York: John Wiley \& Sons; 2000.

19. Gjermo P, Bellini HT, Pereira Santos V, Martins JG, Ferracyoli JR. Prevalence of bone loss in a group of Brazilian teenagers assessed on bite-wing radiographs. J Clin Periodontol. 1984 Feb;11(2):104-13.

20. Wolfe MD, Carlos JP. Periodontal disease in adolescents: epidemiologic findings in Navajo Indians. Community Dent Oral Epidemiol. 1987 Feb;15(1):33-40.

21. Kingman A, Albandar JM. Methodological aspects of epidemiological studies of periodontal diseases. Periodontol 2000. 2002;29:11-30.

22. American Academy of Periodontology (AAP). Position Paper. Periodontal Diseases of Children and Adolescents. J Periodontol. 2003 Nov;74(11):1696-704. 